\title{
Manuel Díaz Rodríguez y el Conflicto entre lo Práctico y lo Ideal
}

SOSTENIA Hipólito Taine - uno de los pensadores favoritos de D. Díaz Rodríguez - que el arte es el resultado del medio ambiente. Esta tesis parece particularmente válida con respecto al arte literario, por cuanto la literatura es ya la producción de un espíritu que se amolda al medio, ya la producción de un espíritu que reacciona al margen o contra ese medio. Por ello, en todo caso, positiva o negativamente, es signo del propio medio.

En consecuencia, al estudiar la obra de Manuel Díaz Rodriguez, prosista venezolano, "el novelista del modernismo", ${ }^{1}$ debería intentarse en primer término situar al artista en el ambiente social de su tierra y de su tiempo.

Nació Díaz Rodríguez en 1868; sus primeras producciones vieron la luz píblica en la revista El Cojo Ilustrado, que había empezado a publicarse en 1892; sus dos primeros libros, Confidencias de Psiquis y Sensaciones de viaje, aparecieron en 1896; su fallecimiento ocurrió en 1927. Así pues, la Venezuela en que desarrolló sus actividades adultas fué, principalmente, la Venezuela de Cipriano Castro y de Juan Vicente Gómez.

Esos regímenes de caudillismo, semi-feudales, brutales, al reaccionar sobre un escritor sólo admiten dos actitudes: la del corifeo o la del rebelde. El mundo literario venezolano ha presentado casos señalados de la primera, el de Laureano Vallenilla, por ejemplo, teorizante de la dictadura en su Cesarismo democrático; ${ }^{2}$ pero también ha producido numerosas personificaciones de rebeldía, y bien señalada fué la de Rufino Blanco-Fombona, por no citar sino una. Ante estas posibles actitudes ¿dónde se sitúa Manuel Díaz Rodríguez? 
Miembro de una familia acomodada, ligada a la oficialidad de su país, Díaz Rodríguez aceptó representar a las dictaduras en el extranjero en cargos diplomáticos y servirlas en Venezuela en puestos de tanta significación como - entre otros-- el de Ministro de Relaciones Exteriores de aquella mojiganga de gobierno que fué el del Presidente "interino" Victorino Márquez Bustillo, bajo la égida de Juan Vicente Gómez, "General en jefe del Ejército" y "Presidente electo" de la República. Es, pues, Manuel Díaz Rodríguez un hombre que, públicamente, se halla situado en el grupo privilegiado venezolano durante una época de regímenes opresivos y nepóticos.

$Y$, sin embargo, si contrastamos esta actitud de su vida diaria con su actitud literaria, no puede dejar de llamarnos la atención la diferencia de tono que existe entre las dos: servidor de un régimen de logreros, predica el desinterés y el idealismo; funcionario de un gobierno de oligarcas, proclama su fe en la juventud y en la rebeldia; colaborador del más inculto y el más retrógrado de los espadones americanos, ensalza la curiosidad y la cultura.

Parece como si Díaz Rodríguez, sometido en lo práctico a aquello que idealmente le repugnaba, buscara en el arte la fórmula escapista, el medio de evasión en que abstraerse del ambiente en que vivían su país y su grupo social.

En la novela Idolos rotos $(1901),{ }^{3}$ por ejemplo, su obra más cruda, nos ofrece el espectáculo de la tragedia de aquella generación venezolana. Es la novela del descentrado, del hombre de progreso en el país del César criollo. Es una crítica del ambiente, dura y clara; pero que acaba con el vencimiento de Alberto Soria, el artista europeizado, y con su desesperación sintetizada en las dos últimas palabras del libro: Finis Patriae. Es una de esas obras que han sido llamadas de choque o de lucha, porque las sensaciones e ideas ajenas al medio hispanoamericano han transformado la idiosincrasia de alguno de los personajes. ${ }^{4}$ Sin embargo, Idolos rotos en su resultado es una novela pesimista, derrotista. Respecto de la actitud social de Díaz Rodriguez en su país y en su tiempo, contiene unas páginas que parecen una oratio pro domo sua, un intento de justificación de su actitud colaboracionista en contraste con la deșesperada reacción de Alberto Soria. Dichas páginas son aquellas en que Emazábel (médico en la novela como Díaz Rodríguez en la realidad, para mayor valor autobiográfico) expone su programa de actuación educativa llevada a cabo por un grupo meramente intelectual dentro del repugnante 
sistema político que él mismo describe y fustiga. ${ }^{5}$ Esta actitud se parece tanto a la adoptada en la vida política por Manuel Díaz Rodríguez, que pudiera ser clave para explicarla. Dice la crítica ${ }^{6}$ que Díaz Rodríguez quiso reflejarse en el personaje Alberto Soria. A nuestro entender resulta más consistente descle un punto de vista psicológico decir que Díaz Rodríguez, hombre desdoblado en su pensamiento y en su acción, se refleja parcialmente en los dos tipos de Alberto Soria y de Emazábel: Soria, el Díaz Rodríguez artista, descentrado, que desespera de su país; Emazábel, el Díaz Rodríguez profesional, político, latifundista, que cede al impulso de clase y que vive en el ambiente que le produce inmediata ventaja, aunque ello sea camuflándose espiritualmente en un propósito reformista.

Deducida así la actitud que pudiéramos llamar práctica de nuestro autor, tratemos ahora de examinar su actitud estética.

Habrá que deducirla, como es natural, del conjunto de sus obras; pero él mismo intentó sintetizarla en una de ellas, a la que llamó Camino de perfección (1908). ${ }^{7}$

Proclama allí su fe en un arte desinteresado, "coraza del ideal". En un mundo, dice, yanquizado, adorador de los solos valores materiales, el artista tiene que refugiarse con su ideal en un arte elevado, de estilo franciscano, quijotesco, a la vez humilde y orgulloso. Frente a su época y a la vida de su época, el "Modernismo" aparece para Díaz Rodríguez no como una escuela o un movimiento puramente de moda literaria, sino casi como un movimiento vital, como una forma necesaria y lógica de expresión de ese arte ideal nuevo que él caracteriza por una tendencia a volver a la materna naturaleza, unida a la complejidad, ansiedad e intensidad del alma moderna ante la vida contemporánea, y a otra tendencia al misticismo. Max Henríquez Ureña, comentando a Díaz Rodríguez, añade a las tendencias señaladas por éste otra, que es la que más brilla en el escritor venezolano, o sea el estilismo, la reivindicación de los derechos de la forma. ${ }^{8}$

Es muy reveladora, además, para la comprensión de Díaz Rodríguez, su definición del misticismo español del Siglo de Oro que, según él, fué:

un franco movimiento de reacción del espíritu de libertad contra el régimen absoluto. El hombre, al sentirse en una atmósfera irrespirable, perseguido, acosado y aun acorralado dentro de su fuero interno por la nefasta presión de una doble tiranía temporal y espiritual, se refugió, a fin de escapar a la 
doble disciplina titánica, dentro de sí mismo; y aquí se dió a recorrer, según puede decirse en la lengua de Teresa de Jesús, las siete moradas de su castillo interior, hasta encontrar y poseer como Teresa bajo los rasgos del Amado, sobre lo más alto del castillo, sobre el ápice de la conciencia, a donde no alcanza el dominio del rey absoluto, ni el ojo sagaz del Tribunal de la $\mathrm{Fe}$, el perfecto señorío de sí propio, la libertad inalienable del espiritu. 9

Trasládase a términos americanos de ayer, y aun de hoy, la anterior declaración y no parece que sea preciso forzar el símil para decir que en ella encaja la actitud estética de Manuel Díaz Rodrígtez.

Por una parte nuestro autor, aunque ahogado por el medio ambiente de su país, acepta trabajar dentro de él, aprovecharse de él y colaborar con lo existente bajo el pretexto, expresado retóricamente por su criatura Emazábel, de influir en su mejoramiento; y, por otra parte, como medio de escapismo a lo Soria, y a la vez como fórmula de compromiso con su propia conciencia, en un intento de conservar ante ella la pureza ideal comprometida por la acción material, afirma el refugio en un arte idealista, en la admiración de la naturaleza, en la exaltación de un misticismo de raigambre tradicional, interpretado a su manera, como forma de mantener aquel "perfecto señorío de sí propio", aquella "libertad inalienable del espíritu" de que nos habla y que no puede existir en la realidad de la vida aceptada y oficial de una Venezuela a lo Castro o a lo Gómez.

A tal intento de separación de la actitud práctica y de la actitud estética débese, a nuestro entender, el hecho de que gran parte de la producción de Manuel Díaz Rodríguez sea una obra musical, una obra de gran estilista, pero incompleta y confusa en su significado y en su filosofía.

Sus primeros libros, como Confidencias de Psiquis (Caracas, 1896), Sensaciones de viaje (París, 1896), De mis romerias (Caracas, 1898), Cuentos de color (Caracas, 1899), son libros esencialmente "literarios", sin más tentativa de mensaje que el del deslumbramiento del artista ante Europa, principalmente ante París y el paisaje italiano.

Los libros que siguen a los mencionados corresponden a la época de la vida de Díaz Rodríguez en que éste empieza a participar activamente en la vida política de su país y en que escucha el canto de sirena de los halagos del poder que le llama y en el que acabará 
por participar, aunque no desconozca que ese poder es corrompido y corruptor, más semejante al de bárbaros caciques que al de su ideal helénico, latino, renacentista. Es la época más definida de Díaz Rodríguez como escritor contradictorio y contradicho consigo mismo; es la etapa de Idolos rotos (París, 1901), Sangre patricia (Caracas, 1902) y Camino de perfección (París, 1908).

Puede luego señalarse en este escritor otra etapa que coincide especialmente con los últimos años de su vida. Dice Angarita Arévalo que es matiz distintivo de la obra "y de la persona de Díaz Rodríguez" "aquel agudo, sobreexcitado sentido del orgullo y de la vanidad" 10 y que Díaz Rodríguez producía su novela Peregrina (Madrid, 1922) "vivida al pie del Avila, entre los amores y las desventuras de nuestros campesinos, mientras el escritor acaso -en examen de conciencia - hallaba que no todo en su vida había sido fecundo..." 11 Estas dos notas, vanidad y orgullo por una parte y desilusión por otra, explican quizá la última manera de Díaz Rodríguez, la que se distingue en Peregrina o El pozo encantado, en los cuentos que con ella aparecieron formando volumen, $y$ en algunas de las notas publicadas póstumamente en Entre las colinas en flor... (Barcelona, 1935). Llegado al máximo de participación en el poder a que podía admitirle un Gómez - gobernador de un Estado, ministro en Venezuela, embajador en Roma-, y hecho el balance de sus méritos, aspiraciones y deseos y el de sus realizaciones, gustadas las desilusiones que el servicio de un déspota trae aparejadas aun a quien le sirva fielmente, es posible que Díaz Rodríguez, sin separarse todavía de la actividad política, pensase que ya tan sólo en la expresión artística podría hallar una culminación su vida, aparentemente triunfadora, quizá intimamente fracasada. $Y$ se refugia en el espectáculo de la vida campesina de Venezuela (aunque vista casi exclusivamente por su lado idílico) presentándola en un estilo casi siempre descargado de vanos perifollos, esencial, claro, lleno ante todo de sentimiento del paisaje y de emoción sin truco.

Parece ésta una posible explicación, psicológica y objetiva a la vez, de las variaciones del estilo de Manuel Díaz Rodríguez y sus etapas: literatismo, choque, nativismo. Puede llegarse a ella al reflexionar sobre el ritmo de su obra y la curva de su vida pública, recordando el principio crítico de Taine antes mencionado y aquella otra tesis tan antigua y siempre nueva de que la forma y el fondo 
de la obra literaria no son entidades separadas y pasivas, sino aglutinadas manifestaciones de idéntico fondo y origen.

En conclusión, Manuel Díaz Rodríguez, poseedor de un indudable poder musical y estilístico, de una visión dura de la realidad y de una exigencia espiritual exquisita, al intentar disociar su vida y su estética en planos de distinta moral entre los que su propia conciencia había de hallar oposición, no alcanzó aquel perfecto ritmo interior indispensable a la producción de la obra de arte perfecta. Con ello perdió la oportunidad de un magisterio americano al que parecía destinado por sus cualidades. Hoy, el lector de sus obras admira en Díaz Rodríguez al magnífico escritor modernista y lamenta a un gran hombre frustrado.

\section{Luis Monguió, Mills College, California.}

\section{NOTAS}

1 Arturo Torres-Rioseco, Grades novelistas de la América hispana, vol. II, Berkeley, California, 1943, p. 63.

2 Laureano Vallenilla, Cesarismo democrático; estudios sobre las bases

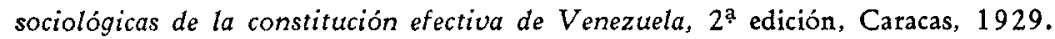

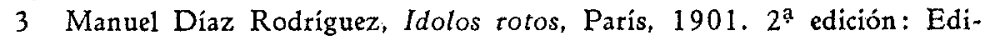
torial América, Biblioteca Andrés Bello, LVI, Madrid, 1919. Las citas de esta novela, en el presente artículo, se hacen por la $2^{\text {a }}$ edición.

4 Arturo Torres-Rioseco, La novela en la América hispana. Berkeley, California, 1941, p. 171.

5 Idolos rotos, pp. 177 y ss.

6 Rafael Angarita Arévalo, Historia y crítica de la novela venezolana, Berlín, 1938, p. 63; Arturo Torres-Rioseco, The epic of Latin American literature, New York, 1942, p. 198; etc.

7 Manuel Díaz Rodríguez, Camino de perfección, Librería de P. Ollendorff, París, 1908.

8 Max Henríquez Ureña, Rodó y Rubén Dario, La Habana, 1918. pp. $81-82$.

9 Camino de perfección, pp. 234-235.

10 Ángarita Arévalo, obra citada, p. 57.

11 Ibid.. p. 67. 